\title{
Killers and victims
}

\section{At a time when children who kill are in the news, a play at London's Cockpit Theatre portrays their disaffected world. Kwame McKenzie reviews.}

Peripheral Violence is an everyday story of Glasgow children who commit murder. Andy has encopresis and enuresis and is playing truant because he has had an 'accident' and is embarrassed. He meets his brother Steve on a motorway fly-over. Steve does not like having his little brother around and tries to get rid of him by chiding him about his 'accident'. He dares Andy to prove himself worthy of staying with him by throwing stones from the fly-over at passing cars. Andy takes up the challenge - an action that has fatal consequences and is the start of a day which ends with another killing.

Written by Robin Lindsay Wilson, directed by Mark Ravenhill and presented by the Soho Theatre Company, Peripheral Violence paints a vivid picture of the lives of brothers Steve and Andy and their schoolmate Natasha. It offers an insight into the minds of the three children: through their eyes we see the failings of the adult world, how children try to make sense of it and how they grow and develop in its chaos.

If harrowing drama can be thought of as enjoyable then I enjoyed the play. Rab Christie and Ronnie McCann gave excellent and believable performances as the young brothers and Susan Webster an equally accomplished depiction of a traumatised and sexually abused girl.

Most people seeing the publicity for the production would think that the play was a shameless exploitation of the James Bulger case. They could not be further from the truth. Robin Wilson wrote it three years ago - after he had finished taking part in writing workshops with Edinburgh school children. (Well before James Bulger had been murdered). He recalls that, returning to Glasgow on a train that ran along the back of Springburn Railway Club, he would see children playing on the fire escapes. The buildings were damp, depressing and forlorn and he wondered what happened there and what the children did to pass time while their parents finished drinking. The play is set in a similar location; the greyness and the unseen adult world pervade the action and make the concrete scenery even more oppressive. There is an ever present threat of unpredictable and powerful adult figures who make, then change the rules, expecting the children to understand and comply. The children live a distressed, anomic existence which you

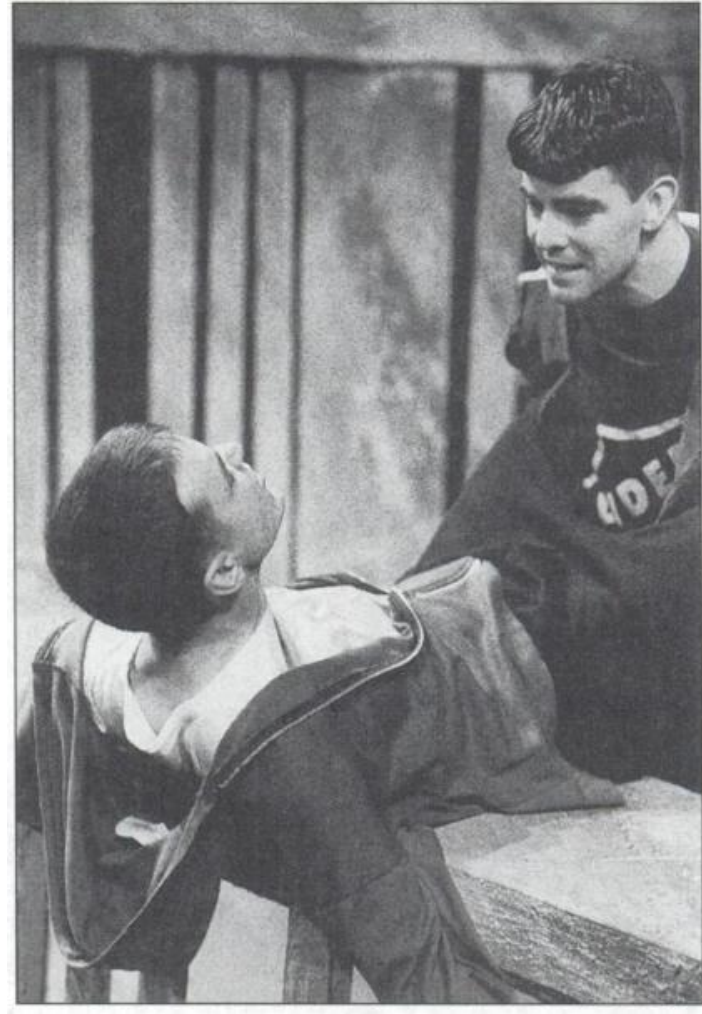

Rab Christie as Andy (left) and Ronnie McCann as Steve (right) in 'Peripheral Violence'. Soho Theatre Company. Copyright: Nick Gurney, Photographer.

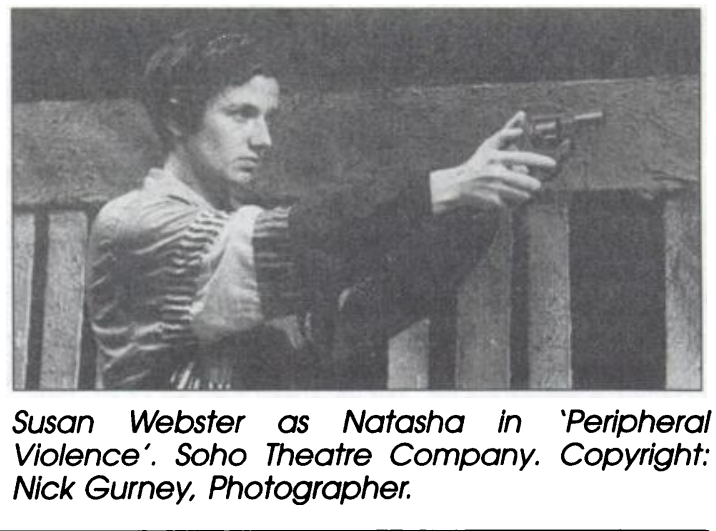


perhaps empathise with more because they are played by adult actors.

The script was passed on to Soho Theatre Company soon after it was finished but this was around the time of the Bulger murder and police investigation. The Company decided to delay production until the case was over. This was not the move of a Theatre Company out to make money but that of a Company which takes art seriously and acts responsibly. It is perhaps not surprising therefore that the Tatler has claimed: "If there is going to be any theatre, apart from musicals, in 20 years time, Soho Theatre Company at the Cockpit (theatre) will probably have been its seed-bed." The play's current run ended in midJune but I am sure that we will see it again soon. Watch out for it.

Kwame McKenzie, Researcher, Institute of Psychiatry, London SE5 8AF

\section{Sun, sea, sand and psychiatry}

Neelam Slsodia and Corinne de Sousa see a message
for psychiatry in a film about Asian women

The denunciation of Gurinder Chadha and Meera Syal's film Bhaji on the Beach by selfstyled leaders of the Asian community on a recent local news programme ensured that we went to see it. Whereas Mira Nair's film Mississippi Masala was dismissed by certain elements of the Asian community in this country because it was set in America and depicted the lives of Ugandan Asians, Bhajt on the Beach is set in Birmingham. It is close to home, grittily authentic and hard to ignore. The film manages to raise many issues, several of which are of considerable relevance to psychiatry, particularly the mental health of women in an ethnic minority.

The title of the film refers to a picnic on the beach when a group of seemingly very different Asian women come together on a day trip to Blackpool. The outing is organised by Simi, an ardent feminist community worker who wears a leather jacket over a Punjabi suit. She runs the Saheli Asian Women's Centre as well as being involved in the Asian Women's refuge, currently home to Ginder and her young son Amrik. Ginder is wrestling with the dilemma of whether she should divorce her husband Ranjit because of violence within their 'love marriage'. She is initially ostracised by the older women in the group for bringing such shame on her family and is later joined 'in Coventry' by Hashida, a budding medical student, previously lauded for her academic achievements and good behaviour. but now found to be pregnant. The sin of premarital sex is compounded by the fact that the father of the baby is of African-Caribbean origin. Hashida and the two younger teenagers are each rebelling in some way. The three middle-aged women in the group have their own inner conflicts and perhaps reflect the teenagers as they might be in later life. Finally there is the spirited elderly woman who is the epitome of a traditional and, at times, more reactionary generation. The story line poignantly demonstrates many of the prejudices and problems faced by women such as these, not least from within their own society. However, as the day progresses the group dynamics change and they begin to understand each other, and no doubt themselves, a little better. Eventually they show acceptance, tolerance and support for one another. Within psychiatric services we also have to demonstrate tolerance and support for patients regardless of age, sex, race, religion and social class. This film carries a message for the planning and provision of these services.

One might expect that as time passes and Asian families become assimilated into British life, problems of race and culture will lessen. This is not necessarily so. In the film Rekha, visiting from Bombay, shows that city dwellers in India are often more broad-minded and tolerant in their outlook than Indians living abroad. The latter may adhere to the values they emigrated with, creating numerous problems for children raised between two cultures. They are trying not only to maintain links with their families and ethnic roots but also to gain acceptance from their adopted community. This can be particularly difficult for girls. In some Asian families male children are held in higher esteem than their female siblings, a legacy of a time when daughters were considered an economic burden because they generated no income but required large dowries upon marriage. While some things have changed for the better, a sense of inferiority among women may be established early in life. 